\title{
URINARY FLUORIDE OUTPUT IN CHILDREN FOLLOWING THE USE OF A DUAL-FLUORIDE VARNISH FORMULATION
}

\author{
Kelly Polido Kaneshiro OLYMPIO ${ }^{1}$, Vanessa Eid da Silva CARDOSO², Maria Fernanda Borro BIJELLA ${ }^{3}$, Juliano Pelim PESSAN ${ }^{4}$, \\ Alberto Carlos Botazzo DELBEM ${ }^{5}$, Marília Afonso Rabelo BUZALAF
}

\begin{abstract}
1- DDS, MSc, PhD Student, Department of Environmental Health, School of Public Health, University of São Paulo, São Paulo, SP, Brazil. 2-DDS, MSc, PhD Student, Department of Biochemistry, Institute of Chemistry, University of São Paulo, São Paulo, SP, Brazil.

3-DDS, MSc, PhD, Department of Public Health and Pediatric Dentistry, Aparício Carvalho Integrated Faculty, RO, Brazil.

4-DDS, MSc, PhD Student, Department of Pediatric Dentistry, Araçatuba Dental School, São Paulo State University, Araçatuba, SP, Brazil. 5-DDS, MSc, PhD, Professor, Department of Pediatric Dentistry, Araçatuba Dental School, São Paulo State University, Araçatuba, SP, Brazil. 6- DDS, MSc, PhD, Professor, Department of Biological Sciences, Bauru School of Dentistry, University of São Paulo, Bauru, SP, Brazil.
\end{abstract}

Corresponding address: Marília Afonso Rabelo Buzalaf - Disciplina de Bioquímica - Departamento de Ciências Biológicas - Faculdade de Odontologia de Bauru - Universidade de São Paulo - Al. Octávio Pinheiro Brisolla, 9-75 - Vila Universitária - 17012-901 - Bauru-SP - Brasil - Phone: 55143227 1486. e-mail: mbuzalaf@fob.usp.br

Received: April 29, 2008 - Modification: August 31, 2008 - Accepted: October 07, 2008

\begin{abstract}
O

bjective: This study evaluated the bioavailability of fluoride after topical application of a dual-fluoride varnish commercially available in Brazil, when compared to Duraphat ${ }^{\mathrm{TM}}$. Material and methods: The urinary fluoride output was evaluated in seven 5year-old children after application of the fluoride varnishes, in two different phases. In the first phase (I), children received topical application of the fluoride varnish Duofluorid XII (2.92\% fluorine, calcium fluoride $+2.71 \%$ fluorine, sodium fluoride, FGMTM). After 1-month interval (phase II), the same amount $(0.2 \mathrm{~mL})$ of the fluoride varnish Duraphat $(2.26 \%$ fluorine, sodium fluoride, Colgate ${ }^{\mathrm{TM}}$ ) was applied. Before each application all the volunteers brushed their teeth with placebo dentifrice for 7 days. Urinary collections were carried out $24 \mathrm{~h}$ prior up to $48 \mathrm{~h}$ after the applications. Fluoride intake from the diet was also estimated. Fluoride concentration in diet samples and urine was analyzed with the fluoride ion-specific electrode and a miniature calomel reference electrode coupled to a potentiometer. Data were tested by ANOVA and Tukey's post hoc test $(\mathrm{p}<0.05)$. Results: There were significant differences in the urinary fluoride output between phases I and II. The use of Duofluorid XII did not significantly increase the urinary fluoride output, when compared to baseline levels. The application of Duraphat caused a transitory increase in the urinary fluoride output, returning to baseline levels $48 \mathrm{~h}$ after its use. Conclusions: The tested varnish formulation, which has been shown to be effective in in vitro studies, also can be considered safe.
\end{abstract}

Key words: Fluorine. Varnishes. Urine. Toxicity. Children.

\section{INTRODUCTION}

Fluoride has been considered an effective anti-caries agent when delivered in many vehicles and concentrations, including a variety of professionally applied fluoride products ${ }^{14}$. Among these products, the use of fluoride varnishes has the advantage of increasing the contact time between fluoride and the tooth surfaces, which improves fluoride uptake by enamel ${ }^{2,9}$. However, some of the product is ingested during placement, despite the rapid setting time and the small dosage used. Duraphat, containing $2.26 \%$ fluorine (or $5 \%$ sodium fluoride), is probably the most commonly used ${ }^{4,6}$. Pessan, et al. ${ }^{8}$ demonstrated that, when fluoride varnish Duraphat was used in 4-7 year-old children, a transitory significant increase in the urinary fluoride output was detected, returning to baseline levels in the last $24 \mathrm{~h}$. Thus, the product can be regarded as safe.
Since 1998, a dual-fluoride varnish manufactured in Brazil has been available in the market (Duofluorid XII, FGM ${ }^{\mathrm{TM}}$ ). The product has a lower cost and has been proved to be effective for caries control in vitro ${ }^{3}$. However, it has a higher fluoride content $(2.92 \%$ fluorine, calcium fluoride $+2.71 \%$ fluorine, sodium fluoride) when compared to a widespread used fluoride varnish (Duraphat, Colgate), which prompted us to investigate its fluoride bioavailability after topical application in children. Considering that the urine is the main excretion route for ingested fluoride ${ }^{13}$, urinary fluoride excretion was used to assess the fluoride bioavailability.

\section{MATERIAL AND METHODS}

Seven children aged 5 years old ( \pm 6 months, 3 males and 4 females) took part in this study. Children were selected at 
the Pediatric Dentistry Clinic from Bauru Dental School, University of São Paulo. All the children lived in a fluoridated area (Bauru, SP, Brazil, 0.6-0.8 mg fluoride/L in the drinking water), had good oral health and were not using medicines. Children that had focal infections, residual roots or many cavitated lesions did not participate. The protocol of the study was reviewed and approved by the Institutional Review Board (IRB) of the Bauru School of Dentistry, University of São Paulo. The aims of the study were explained verbally and in writing to the parents who signed an IRB-approved informed consent document.

\section{Study Protocol}

The study had two different experimental periods (phase I and phase II). The children used a placebo dentifrice (without fluoride) for 7 days before each phase. In phase I, the volunteers received an application of the test fluoride varnish (Duofluorid XII, FGM ${ }^{\mathrm{TM}}$ ), Joinville, SC, Brazil), based on synthetic resin and ethanol as solvent, containing $6 \%$ calcium fluoride and $6 \%$ sodium fluoride (5.63\% fluorine). This fluoride varnish has a transparent color, presenting the advantage of not influencing the esthetic appearance. After a washout period of 30 days, in phase II, the same children received an application of the control fluoride varnish (Duraphat, Colgate $^{\mathrm{TM}}$, A. Nattermann $\mathrm{GmbH}$, Germany) based on colophony resin and containing $5 \%$ sodium fluoride (2.26\% fluorine), according to the manufacturer. It has a yellowish-brown color and adheres to tooth surfaces for several hours after application.

Before the applications, the teeth were thoroughly cleaned with pumice, sprayed with water and air-dried. The varnish was applied at 9 a.m., using a small brush and starting with the interdental areas. All tooth surfaces were subsequently covered. To facilitate the final setting of the varnish, the teeth were carefully rinsed with water and this was sucked up. The children were told to avoid solid foods during the first $4 \mathrm{~h}$ following application and to refrain from brushing their teeth until the next morning. Thus, the children only brushed their teeth once in the day that the fluoride varnish was applied. The amount of varnish used was $0.2 \mathrm{~mL}$ per child.

\section{Urinary Sample Collections}

Urine was collected during the $24 \mathrm{~h}$ period prior to the use of fluoride varnish (control day) until $48 \mathrm{~h}$ thereafter, for both phases.

The protocol for urinary collection described by Villa, et al. ${ }^{11}$ was followed. Children were instructed to void their urine only in their individual labeled wide-necked plastic vessels. Urine sample collection (control day) started at 9:00 a.m. and vessel 1, containing all the urine collected up to 9:00 p.m., was closed and brought to our laboratory, where the volume of each individual sample was immediately determined. An aliquot $(50 \mathrm{~mL})$ was frozen $\left(-20^{\circ} \mathrm{C}\right)$ until fluoride analysis. Vessel 2 contained all individual urine collected from 9:00 p.m. until 9:00 a.m. of the following (test) day, when the application of fluoride varnish was carried out. From then on, all individual urine voidings from each child were collected following the same pattern as previously described for the control day, for additional $48 \mathrm{~h}$ (vessels 3 to 6). All flasks containing urine samples were kept permanently closed in a refrigerator until they were brought to the laboratory.

\section{Estimation of Fluoride Intake from Diet}

In order to estimate the total fluoride intake of the children at the experimental day, fluoride ingested from diet was determined, and "duplicate-plate" samples of all foods and beverages ingested during one day were collected, as described by Guha-Chowdhurry, et al. ${ }^{5}$. The duplicate diets were collected at the children's houses. As the children refrained from brushing their teeth after varnish application, the estimation of fluoride ingested from dentifrice was not necessary.

The parents were instructed not to offer their children hard foods, in order to not remove the varnish in the $24 \mathrm{~h}$ after the applications. The diet was duplicated as precisely as possible by observing the amounts that the children had really eaten and drunk. Parents were requested to remove parts of foods not normally eaten, such as seeds, cores, skin, and bones, before including the food in the container.

Parents were asked to use household measures, such as teaspoon, table spoon, or cupful, to approximate quantities of food ingested. In the case of cooked meals, parents were asked to serve 2 similar portions on 2 separate plates, to wait until the children had finished their portion, and to add or remove comparable portions on the separate plate.

The diet was homogenized using deionized water, the total volume was measured and an aliquot sample of $50 \mathrm{~mL}$ was taken and frozen $\left(-20^{\circ} \mathrm{C}\right)$ until analysis.

\section{Fluoride Analysis}

Fluoride analysis in the urine samples was determined using an ion-specific electrode (Model 9609, Orion Research Inc., Cambridge, MA, USA), after sample buffering with an equal volume of TISAB II. Standards were prepared by serial dilution of $100 \mathrm{ppm}$ sodium fluoride stock solution (Orion Research Inc., Beverly, MA, USA). The standard curve had a coefficient correlation $=0.99$. The mean repeatability of the readings, based on duplicate samples, was $96 \%$.

Fluoride concentrations in the diet samples were determined after overnight hexamethyldisiloxane (HMDS)facilitated diffusion ${ }^{10}$ as modified by Whitford ${ }^{12}$ using the fluoride ion-specific electrode (Orion 9409, Orion Research Inc., Beverly, MA, USA) and a miniature calomel reference electrode (Accumet, \#13-620-79, Fisher Scientific, Pittsburgh, PN, USA), coupled to a potentiometer (Orion Research Inc., model EA 940, Beverly, MA, USA). During the diffusion process, which was conducted at room temperature, the solutions in the non-wettable Petri dishes (Falcon, No. 1007, Becton Dickinson Labware, Lincoln Park, NJ, USA) were gently swirled on a rotatory shaker. Fluoride standards $(0.0095,0.019,0.095$ and $0.190 \mu \mathrm{g}$ fluoride) were prepared by serial dilution of a stock solution of $0.1 \mathrm{M}$ fluoride (Orion Research Inc., 940906, Beverly, MA, USA) in triplicate and diffused in the same manner as the samples. Comparison with identical nondiffused fluoride standards showed that recovery 
after diffusion was $>99 \%$. The standard curve had a correlation coefficient $=0.99$. All samples were analyzed in duplicate. The mean repeatability of the readings, based on duplicate samples, was $90 \%$.

\section{Statistical Analysis}

The software GraphPad Prism version 4.0 for Windows (GraphPad Inc., La Jolla, CA, USA) was used. For analysis, 12-h urinary data were combined, so that 24-h data were obtained. Fluoride excreted in urine at the first $24 \mathrm{~h}$ (control day) was compared with fluoride excreted $24 \mathrm{~h}$ (experimental day) and $48 \mathrm{~h}$ thereafter using two-way repeated measures ANOVA and Tukey's post hoc test. The comparison of fluoride intake from the diet in the two phases was made using paired $t$ test. The comparison of the urinary $\mathrm{pHs}$ among the collection and between the phases was done using two-way repeated measures ANOVA. A significance level of 5\% was adopted in all cases.

\section{RESULTS}

Table 1 and Figure 1 show, respectively, the individual and mean amounts of fluoride excreted in urine in the control day (baseline), as well as at the 24 and $48 \mathrm{~h}$ following the application of the varnishes. As can be depicted from Table 1 , the results showed a wide variation among the subjects for each collection. For volunteers $\mathrm{C}$ and $\mathrm{F}$, high baseline urinary

TABLE 1- Individual and mean amount of fluoride excreted (mg/day) in urine before and after application of Duofluorid XII ${ }^{\mathrm{TM}}$ and Duraphat ${ }^{\mathrm{TM}}$ varnishes

\begin{tabular}{|c|c|c|c|c|c|c|}
\hline $\begin{array}{l}\text { Children } \\
\text { codes }\end{array}$ & $\begin{array}{l}24 \mathrm{~h} \text { before } \\
\text { application }\end{array}$ & $\begin{array}{l}\text { Duofluorid XII } \\
24 \text { h after } \\
\text { application }\end{array}$ & $\begin{array}{l}48 \mathrm{~h} \text { after } \\
\text { application }\end{array}$ & $\begin{array}{l}24 \mathrm{~h} \text { before } \\
\text { application }\end{array}$ & $\begin{array}{l}\text { Duraphat } \\
24 \mathrm{~h} \text { after } \\
\text { application }\end{array}$ & $\begin{array}{l}48 \mathrm{~h} \text { after } \\
\text { application }\end{array}$ \\
\hline A & 0.186 & 0.260 & 0.150 & 0.284 & 0.471 & 0.186 \\
\hline B & 0.240 & 0.456 & 0.225 & 0.266 & 0.907 & 0.260 \\
\hline C & 0.381 & 0.267 & 0.209 & 0.434 & 0.674 & 0.155 \\
\hline $\mathrm{D}$ & 0.255 & 0.499 & 0.480 & 0.299 & 0.435 & 0.458 \\
\hline$E$ & 0.233 & 0.578 & 0.366 & 0.244 & 0.631 & 0.270 \\
\hline$F$ & 0.490 & 0.190 & 0.248 & 0.188 & 0.818 & 0.255 \\
\hline G & 0.186 & 0.290 & 0.257 & 0.240 & 0.447 & 0.227 \\
\hline Mean & $0.282^{a}$ & $0.363^{a}$ & $0.276^{a}$ & $0.279^{a}$ & $0.626^{b}$ & $0.259^{a}$ \\
\hline $\begin{array}{l}\text { Standard } \\
\text { Deviation }\end{array}$ & 0.113 & 0.146 & 0.111 & 0.077 & 0.187 & 0.097 \\
\hline
\end{tabular}

Different letters indicate statistically significant difference $(p<0.05)$.

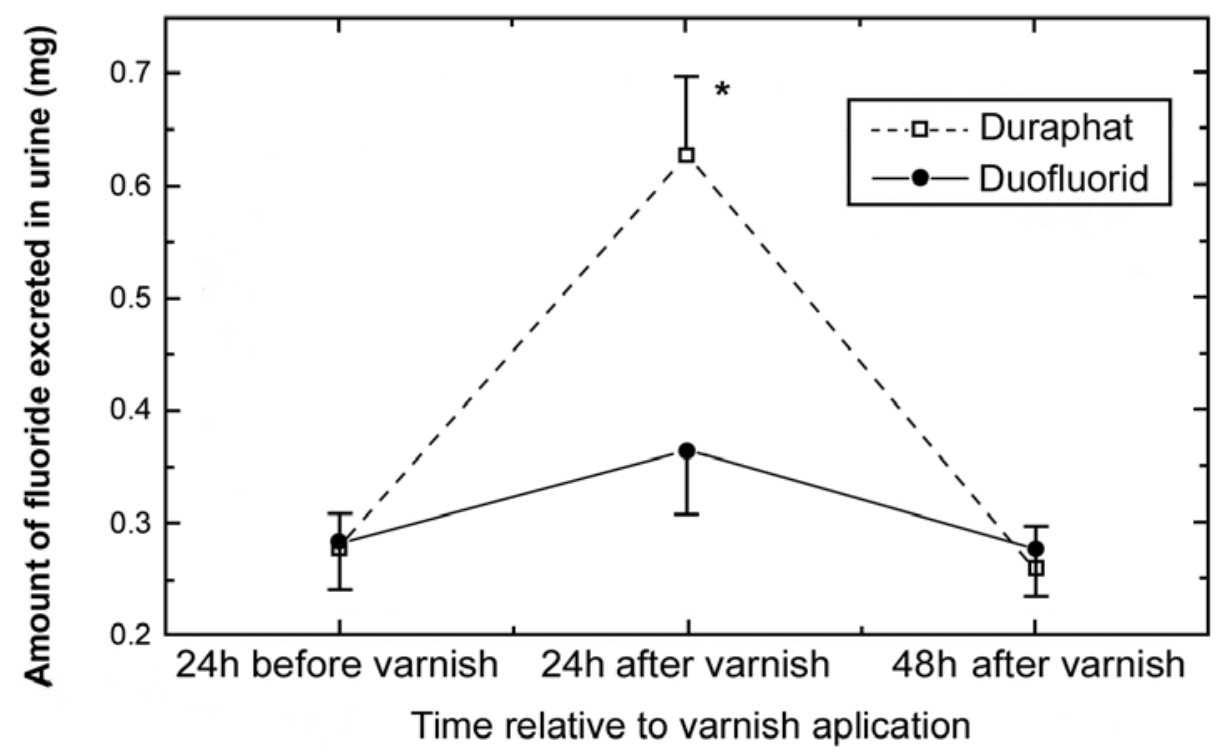

FIGURE 1- Means of the amount of fluoride excreted in urine before varnishes application, and after $24 \mathrm{~h}$ and $48 \mathrm{~h}$. Bars indicate standard error of means. * shows a significant difference from the other values (two-way repeated measures ANOVA, p<0.05) 
TABLE 2- Fluoride intake (mg) from the diet and $\mathrm{pH}$ values of the 6 urine samples collected, for each volunteer (Vol) at phases I (Duofluorid) and II (Duraphat)

\begin{tabular}{|c|c|c|c|c|c|c|c|c|c|c|c|c|c|c|}
\hline \multirow[t]{3}{*}{ Vol } & \multicolumn{2}{|c|}{$\begin{array}{l}\text { F intake } \\
\text { from diet }\end{array}$} & \multicolumn{12}{|c|}{ Urine $\mathrm{pH}$} \\
\hline & \multirow[b]{2}{*}{ I } & \multirow[b]{2}{*}{ II } & \multicolumn{2}{|c|}{$1^{\text {st }}$} & \multicolumn{2}{|c|}{$2^{\text {nd }}$} & \multicolumn{2}{|c|}{$3^{\text {rd }}$} & \multicolumn{2}{|c|}{$4^{\text {th }}$} & \multicolumn{2}{|c|}{$5^{\text {th }}$} & \multicolumn{2}{|c|}{$6^{\text {th }}$} \\
\hline & & & I & II & I & II & I & II & I & II & I & II & I & II \\
\hline A & 0.10 & 0.09 & 6.8 & 6.9 & 5.5 & 6.1 & 7.0 & 7.8 & 5.6 & 6.5 & 6.6 & 6.6 & 5.5 & 6.6 \\
\hline B & 0.16 & 0.09 & 7.5 & 6.7 & 7.5 & 6.4 & 7.7 & 7.0 & 7.0 & 6.5 & 6.6 & 7.1 & 6.7 & 6.5 \\
\hline C & 0.52 & 0.23 & 6.5 & 6.3 & 6.1 & 6.0 & 6.5 & 6.8 & 5.5 & 5.5 & 6.4 & 5.8 & 6.6 & 5.3 \\
\hline D & 0.42 & 0.22 & 5.7 & 7.0 & 5.5 & 5.5 & 6.7 & 7.0 & 7.5 & 5.9 & 6.9 & 7.0 & 6.0 & 5.9 \\
\hline$E$ & 0.30 & 0.34 & 6.9 & 6.7 & 6.5 & 7.0 & 6.7 & 6.5 & 6.3 & 6.6 & 6.5 & 6.1 & 6.7 & 6.5 \\
\hline $\mathbf{F}$ & 0.46 & 0.37 & 5.6 & 6.5 & 5.5 & 6.0 & 6.5 & 6.1 & 5.7 & 5.9 & 6.7 & 7.0 & 5.9 & 5.5 \\
\hline G & 0.05 & 0.16 & 6.8 & 6.6 & 6.3 & 6.5 & 7.0 & 5.7 & 6.8 & 6.6 & 6.5 & 6.0 & 6.8 & 6.7 \\
\hline Mean & 0.29 & 0.21 & 6.5 & 6.7 & 6.1 & 6.2 & 6.9 & 6.7 & 6.3 & 6.2 & 6.6 & 6.5 & 6.3 & 6.1 \\
\hline SD & 0.19 & 0.11 & 0.7 & 0.2 & 0.7 & 0.5 & 0.4 & 0.7 & 0.8 & 0.4 & 0.2 & 0.5 & 0.5 & 0.6 \\
\hline
\end{tabular}

The difference between phase I and phase II was not significant either for fluoride intake from diet or urinary $\mathrm{pH}(\mathrm{p}>0.05)$.

fluoride values were detected when Duofluorid XII was used and no numerical increases were found after its application. For all the other situations, increases in urinary fluoride were detected $24 \mathrm{~h}$ after the varnishes were applied. When Duraphat was used, a significant increase in mean urinary fluoride excretion was observed $(0.626 \pm 0.187 \mathrm{mg}$ /day $)$, returning to baseline levels $(0.279 \pm 0.077 \mathrm{mg} /$ day $)$ in the subsequent $24 \mathrm{~h}$ $(0.259 \pm 0.097 \mathrm{mg} /$ day $)$. As for Duofluorid XII, there was only a slight increase in the mean amount of fluoride excreted after the varnish was used $(0.363 \pm 0.146 \mathrm{mg} / \mathrm{day})$, which did not differ from baseline $(0.282 \pm 0.113 \mathrm{mg} /$ day $)$ and the subsequent day $(0.276 \pm 0.111 \mathrm{mg} /$ day $)$. In addition, the amount of fluoride excreted in urine when Duraphat was used was significantly higher when compared to Duofluorid XII.

Table 2 shows the values of fluoride intake $(\mathrm{mg})$ from the diet and $\mathrm{pH}$ values of the 6 urine samples collected, for each volunteer, as well as the means. The mean fluoride intake from diet $( \pm \mathrm{SD})$ at phases I and II was $0.288 \pm 0.186 \mathrm{mg} /$ day and $0.214 \pm 0.112 \mathrm{mg} /$ day, respectively. There was no significant difference between the phases $(t=1.43, \mathrm{p}=0.203)$. The mean $\mathrm{pH}$ of the samples $( \pm \mathrm{SD})$ ranged between $6.1 \pm 0.7$ and $6.9 \pm 0.4$ for phase $I$ and between $6.1 \pm 0.6$ and $6.7 \pm 0.7$ for phase II. There was no significant difference among the collections $(\mathrm{F}=2.207, \mathrm{p}=0.075)$ or between the phases $(\mathrm{F}=0.323, \mathrm{p}=0.573)$.

\section{DISCUSSION}

Taking into account the toxicological aspect, regular swallowing of low doses of fluoride from several sources by small children has been associated with the development of mild dental fluorosis ${ }^{7}$. In this context, a careful vigilance on new fluoride products is necessary. Among these products, Duofluorid XII (FGMTM), a dual-fluoride varnish manufactured in Brazil, has been available in the market. Its efficacy has been demonstrated in in vitro studies using a $\mathrm{pH}$-cycling system ${ }^{3}$. This varnish has been shown to be as effective as Duraphat to reduce demineralization of bovine enamel blocks ${ }^{3}$. This, in addition to the low cost of the product, could increase its use in private and public clinical practices. Since Duraphat has $2.26 \%$ fluoride and Duofluorid XII has $5.63 \%$ fluoride, concern has been arisen regarding the toxicological potential of this product, especially in children.

Twenty-four hour urinary fluoride excretion was chosen as the response variable to evaluate the bioavailability of fluoride from the products tested. This was done because the kidneys are the major route for the excretion of fluoride ${ }^{12}$. Since the volunteers used a fluoride-free dentifrice before and during the study, and the amount of estimated fluoride ingested from the diet was not significantly different between the phases, any increase in the fluoride excreted in urine could be attributed to the tested products.

In this study, significant differences in the mean urinary fluoride excretion between the varnishes tested were found. Duraphat produced a significant increase in urinary fluoride output, which returned to baseline levels in the subsequent $24 \mathrm{~h}$. Similar values (around $600 \mu \mathrm{g}$ ) have already been described by Pessan, et al. ${ }^{8}$. Despite this transient increase, Duraphat can be regarded as safe, because the baseline values were rapidly reestablished both for the mean and individual values. In addition, Baez, et al. ${ }^{1}$ suggested that urinary fluoride excretion rates of $0.4-0.5 \mathrm{mg} /$ day in children of 3-6 years would be considered an indication of "optimal" fluoride intake. One point that calls attention when Table 1 is observed is that for volunteers C and F, when Duofluorid XII was used it was not possible to detect a numerical increase in urinary fluoride levels after $24 \mathrm{~h}$. It is also noteworthy that for these volunteers high baseline urinary fluoride levels were detected, which may have led to this result. The high baseline fluoride levels can be partially explained by the higher fluoride intake in this day, especially for volunteer F (Table 2). The lower 
urinary $\mathrm{pH}$ observed for volunteers $\mathrm{C}$ and $\mathrm{F}$ at the $4^{\text {th }}$ urinary collection (Table 2) may help to explain the lower urinary fluoride excretion observed for these volunteers $24 \mathrm{~h}$ after the use of Duofluorid XII. This is due to the fact that when the $\mathrm{pH}$ in the renal tubules is low, a higher amount of HF is present. This molecule can readily cross the wall of the renal tubules, returning to the systemic circulation, which decreases the amount of fluoride that would remain in the renal tubules to be excreted in urine. ${ }^{12}$. Regardless the cause of this lower urinary fluoride excretion, the lack of numeric increase in urinary fluoride excretion after the application of Duofluorid XII for these volunteers is, in a certain way, a confirmation of the safety of this product.

As Duofluorid XII presents 2.45 times more fluoride than Duraphat, it was expected to induce higher circulating fluoride levels, which, in turn, would increase urinary fluoride excretion. However, it caused only a slight increase in the amount of fluoride excreted in urine ( $81 \mu \mathrm{g}$ /day) and this amount did not significantly differ from baseline. This apparent discrepancy may be explained by a combination of factors. First, the number of volunteers in each group might have not been enough. This, however, does not seem to be the reason since there was a significant increase in urinary fluoride when Duraphat varnish was used. Second, the possible complexation between fluoride and the synthetic resin or the ethanol present in Duofluorid's XII formulation may have led to this result. Third, there could have been a higher fluoride uptake by the body tissues, after the use of Duofluorid XII, which does not seem to have occurred because the study had a crossover protocol, with the same volunteers participating in both phases. Fourth, the interactive effects between calcium fluoride and sodium fluoride present in Duofluorid XII assure that it promptly reacts with the teeth surface, maximizing its anti-cariogenic effects, thus minimizing the fluoride systemic bioavailability. Duofluorid XII formulation has fluoride as calcium fluoride (6\%) and sodium fluoride $(6 \%)$. According to the manufacturer, calcium fluoride is added in order to increase the potential of calcium fluoride formation on the teeth, by driving the reaction to the precipitation on the teeth. In addition, the presence of calcium fluoride in the varnish could avoid that the calcium fluoride formed on the teeth migrate to the varnish, improving the fluoride deposited on the teeth. This is consistent with the fact that the application of Duofluorid XII in vitro led to a higher surface microhardness of enamel blocks when compared to Duraphat, despite this difference was not significant ${ }^{3}$. Furthermore, despite Duofluorid XII contains a higher fluoride amount, the quantity of fluoride that is soluble in saliva may be similar to other varnishes like Duraphat, because the amount of fluoride added as sodium fluoride is almost the same. If these assumptions are true, the addition of calcium fluoride to topical application fluoride products could be a good alternative to increase the delivery of fluoride to enamel, without increasing the risk of toxicity of the product. However, further investigation to support this assumption is required.

\section{CONCLUSIONS}

The tested dual-fluoride varnish formulation is safe to be used in children.

\section{REFERENCES}

1- Baez RL, Baez MX, Marthaler TM. Urinary fluoride excretion by children 4-6 years old in a south Texas community. Pan Am J Public Health. 2000;7(4):242-8.

2- Beltran-Aguilar ED, Goldstein JW, Lockwood SA. Fluoride varnishes. A review of their clinical use, cariostatic mechanism, efficacy and safety. J Am Dent Assoc. 2000;131(5):589-96.

3- Brighenti FL, Oliveira FAL, Sassaki KT, Buzalaf MAR, Pessan JP, ten Cate JM, et al. Fluoride varnishes: anticariogenic action of an experimental coat in vitro. Caries Res. 2006;40(3):316.

4- Elwood R, Fejreskov O. Clinical use of fluoride. In: Fejerskov O, Kidd EAM (ed). Dental caries: the disease and its clinical management. Oxford: Blackwell Munksgaard; 2003.p.189-222.

5- Guha-Chowdhury N, Drummond BK, Smillie AC. Total fluoride intake in children aged 3 to 4 years - a longitudinal study. J Dent Res. 1996;75(7):1451-7.

6- Helfenstein U, Steiner M. Fluoride varnishes (Duraphat): a meta-analysis. Community Dent Oral Epidemiol. 1994;22(1):1-5.

7- Koch G, Petersson LG, Kling E, Kling L. Effect of 250 and 1000 ppm fluoride dentifrice on caries. A three-year clinical study. Swed Dent J. 1982;6(6):233-8.

8- Pessan JP, Pin MLG, Martinhon CCR, Silva SMB, Granjeiro JM, Buzalaf MAR. Analysis of fingernails and urine as biomarkers of fluoride exposure from dentifrice and varnish in 4-7-year-old children. Caries Res. 2005;39(5):363-70.

9- Seppä L. Efficacy and safety of fluoride varnishes. Comp Cont Educ Dent. 1999;20(1 Suppl):18-26.

10- Taves DR. Separation of fluoride by rapid diffusion using hexamethyldisiloxane. Talanta. 1968;15(9):969-74.

11- Villa A, Salazar G, Anabalón M, Cabezas L. Estimation of the fraction of an ingested dose of fluoride excreted through urine in pre-school children. Community Dent Oral Epidemiol. 1999;27(4):305-12.

12- Whitford GM. The Metabolism and toxicity of fluoride. Myers HM (ed): $2^{\text {nd }}$ ed, Basel: Karger; 1996.

13- World Health Organization. Fluorides and Oral Health. Technical Report Series No. 846. Geneva: WHO; 1994.

14- Zimmer S. Caries-preventive effects of fluoride products when used in conjunction with fluoride dentifrice. Caries Res. 2001;35(1Suppl):18-21. 